\title{
Endoscopic ultrasound for ascariasis in common bile duct
}

Biliary ascariasis is a common problem in tropical countries. Diagnosis requires a high index of suspicion in patients from an area where the condition is endemic and who present with obstructive jaundice. Abdominal ultrasonography, which is the first modality for evaluation of such patients, can allow biliary ascariasis to be diagnosed in $85 \%$ of cases. The characteristic sonographic features of worms in the common bile duct (CBD) are multiple, long, linear, parallel echogenic strips, usually without acoustic shadowing [1]. Computed tomography and magnetic resonance imaging (MRI) show "bull's-eye" and "eye-glass" appearances of Ascaris in the CBD [2]. Endoscopic retrograde cholangiopancreatography (ERCP), considered the gold standard for diagnosis of biliary ascariasis, should be reserved for therapeutic rather than diagnostic use as papillotomy can lead to reentry of the worm into the CBD [3]. Endoscopic ultrasonography (EUS) is now considered the most sensitive method for evaluation of a dilated CBD [4] and has been reported to demonstrate the presence of biliary ascariasis in one case [5].

A 25-year-old lady presented with complaints of abdominal pain and fever. Laboratory investigations revealed the following: total leukocyte count $14800 / \mu \mathrm{L}$, alanine transaminase $308 \mathrm{U} / \mathrm{L}$, aspartate transaminase $356 \mathrm{U} / \mathrm{L}$, serum alkaline phosphatase $584 \mathrm{U} / \mathrm{L}$, and serum bilirubin $3.1 \mathrm{mg} / \mathrm{dL}$. Abdominal ultrasonography revealed a dilated $\mathrm{CBD}$ with ill-defined echogenic shadows. EUS was considered before ERCP to evaluate the echogenic shadows, and was performed using a linear echoendoscope (3830 UT; Pentax Corp., Tokyo, Japan). It revealed a longitudinal hyperechoic shadow $4 \mathrm{~cm}$ in length, coiling once in the CBD, confirming the diagnosis of biliary ascariasis. This longitudinal shadow had two classical hyperechoic linear echogenic strips on either side of the longitudinal anechoic lumen of the ascaris ( $\bullet$ Figs. 1, 2). The diameter of the bile duct and the shadow were measured at $8 \mathrm{~mm}$ and $3 \mathrm{~mm}$ respectively ( $\mathbf{F i g . 3}$ ). ERCP was performed to remove the worm from the bile duct.

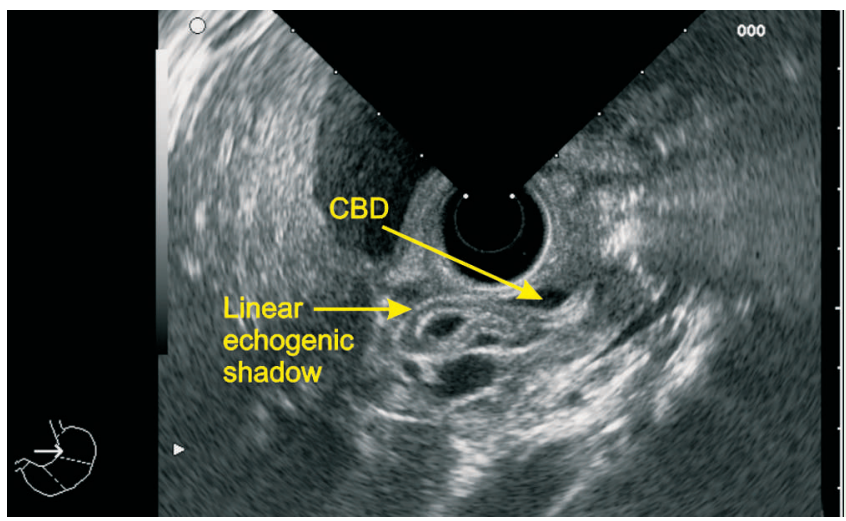

Fig. 1 A coiled-up linear echogenic shadow was shown in the common bile duct.

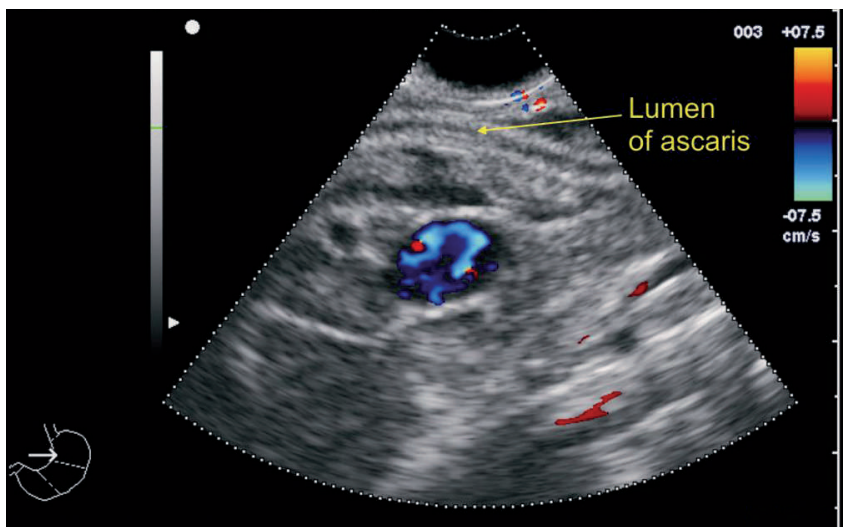

Fig. 2 The lumen of the shadow was identified and a diagnosis of ascariasis in the common bile duct was made.

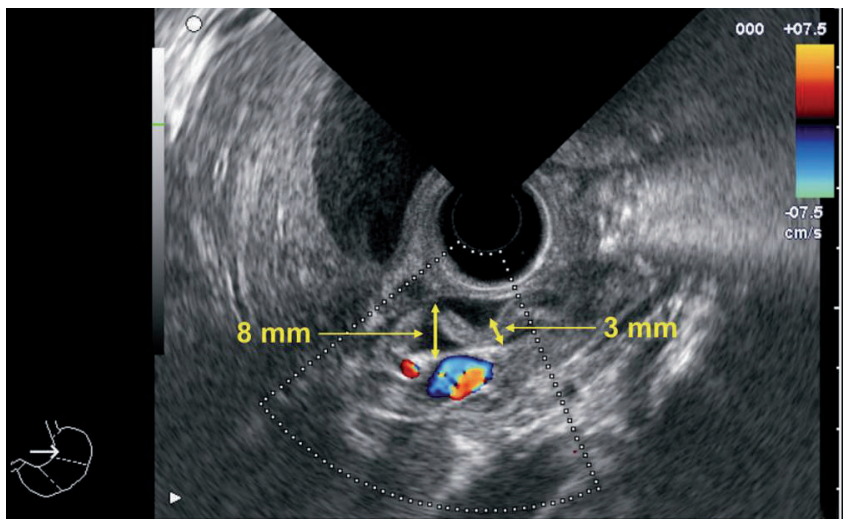

Fig. 3 The diameter of common bile duct was $8 \mathrm{~mm}$ and the diameter of the linear echogenic shadow was $3 \mathrm{~mm}$.

The demonstration of characteristic findings shows that EUS should be routinely used before ERCP in cases of dilated CBD to diagnose biliary ascariasis in areas where this condition is endemic.

Endoscopy_UCTN_Code_CCL_1AF_2AF_3AZ

\section{Sharma, S. Garg}

Jaswant Rai Speciality Hospital, Saket, Meerut-250 001, Uttar Pradesh, India 


\section{References}

1 Khuroo MS, Zargar SA, Mahajan R. Hepatobiliary and pancreatic ascariasis in India. Lancet 1990; 335: $1503-1506$

$2 \mathrm{Ng} \mathrm{KK}$, Wong HF, Kong MS et al. Biliary ascariasis: CT, MR cholangiopancreatography, and navigator endoscopic appearance - report of a case of acute biliary obstruction. Abdom Imaging 1999; 24: 470-472

3 Sandouk F, Haffar S, Zada MM et al. Pancreatic-biliary ascariasis: experience of 300 cases. Am J Gastroenterol 1997; 92: 2264 2267
4 Stabuc B, Drobne D, Ferkolj I et al. Acute biliary pancreatitis: detection of common bile duct stones with endoscopic ultrasound. Eur J Gastroenterol Hepatol 2008; 20: $1171-1175$

5 Mijandrušič-Sinčič B, Štimac D, Kezele B et al. Acute pancreatitis caused by Ascaris lumbricoides: a case report. Gastrointest Endosc 2008; 67: $541-542$
Bibliography

DOI $10.1055 / \mathrm{s}-0029-1214797$

Endoscopy 2009; 41: E209-E210

(c) Georg Thieme Verlag KG Stuttgart · New York . ISSN 0013-726X

Corresponding author

\section{Sharma, MD, DM}

Jaswant Rai Speciality Hospital

Saket

Meerut-250 001

Uttar Pradesh

India

sharmamalay@hotmail.com 